\title{
Epidemiology of extrapulmonary tuberculosis in Brazil: a hierarchical model
}

\author{
Teresa Gomes ${ }^{1}$, Bárbara Reis-Santos ${ }^{1}$, Adelmo Bertolde ${ }^{2}$, John L Johnson ${ }^{3}$, Lee W Riley ${ }^{4}$ and Ethel Leonor Maciel ${ }^{*}$
}

\begin{abstract}
Background: Although extrapulmonary tuberculosis (EPTB) is less frequent than Pulmonary Tuberculosis (PTB) and is a secondary target for national TB control programs, its significance has increased worldwide during the HIV epidemic. The objective of this study was to examine the epidemiology of EPTB in Brazil between 2007 and 2011.

Methods: Cross-sectional study involving all cases of TB reported to the Brazilian Notifiable Diseases Surveillance System (Sistema de Informações de Agravo de Notificação - SINAN) in Brazil between 2007 and 2011.

Sociodemographic and clinical characteristics of patients with exclusively PTB and exclusively EPTB were compared. Following analysis with Pearson's chi-square test, variables with $p<0.05$ were included in a hierarchical regression model. Variables with $p<0.05$ in the corresponding level were kept in the model.

Results: A total of 427,548 cases of TB were included. Of these, 356,342 cases (83.35\%; $95 \%$ confidence interval (Cl) 83.23\% - 83.45\%) were PTB, 57,217 (13.37\%; 95\% Cl 13.28\% - 13.48\%) were EPTB, 13,989 (3.27\%; 95\% Cl 3.21\% - 3.32\%) were concurrent pulmonary and extrapulmonary TB. Patients with EPTB were mainly white (16.7\%), and most (29.1\%) patients had five to eight years of education. Among comorbidities, HIV infection was prominent (OR 2.15; 95\% Cl $2.09-2.21$ ), although the proportion of cases awaiting test results or untested was high (39\%). Ethanol use (OR 0.45; 95\% Cl $0.43-0.46)$, diabetes mellitus (OR 0.54; 95\% Cl $0.51-0.57$ ) and mental illness (OR 0.88; $95 \% \mathrm{Cl}$ 0.82 - 0.95) were associated with PTB.
\end{abstract}

Conclusions: Thirteen percent of patients diagnosed with TB in Brazil have only EPTB. More effective diagnostic strategies and control measures are needed to reduce the number of cases of extrapulmonary TB in Brazil.

\section{Background}

Although data are limited, extrapulmonary disease is a common presentation of tuberculosis (TB) in Brazil. In 2011, 14\% of all cases of TB reported to the World Health Organization (WHO) were extra-pulmonary TB (EPTB) [1].

A national literature search demonstrated that the epidemiology of EPTB is infrequently mentioned. ЕPTB is rarely included in publications on the epidemiological profile of TB $[2,3]$. Two studies at the national level mention EPTB only when discussing TB in persons coinfected with human immunodeficiency virus (HIV) $[4,5]$. Studies have addressed EPTB at the level of states [6], municipalities $[4,7]$, and healthcare services $[5,8]$ in Brazil, but none have addressed it at the national level.

\footnotetext{
* Correspondence: ethel.maciel@gmail.com

'Laboratory of Epidemiology, Universidade Federal do Espírito Santo, Vitória, ES, Brazil

Full list of author information is available at the end of the article
}

This situation is illustrated by the omission of EPTB from the latest epidemiological report on TB by the Brazilian Health Ministry published in 2012 [9].

The rate of EPTB in Brazil increased from 6.8 per 100,000 people in 1981 to 7.0 per 100,000 people in 1991. A study conducted in the municipality of Campinas, São Paulo between 2001 and 2009 found a 23.7\% reduction in the number of cases of pulmonary TB (PTB) but only a $5.9 \%$ reduction in the number of cases of EPTB [4].

One of the main factors affecting the rate of EPTB in Brazil is the HIV/AIDS epidemic because the development of EPTB is favored by HIV infection and other conditions that suppress immune function [10].

Due to the impact of the HIV epidemic on EPTB, the scarcity of national studies of EPTB, and the relevance of EPTB to the epidemiology of TB and TB control in Brazil, the present study was done to examine the epidemiology of EPTB in Brazil during the five year period from 2007 to 2011.

\section{Biomed Central}




\section{Methods}

Information systems are essential tools for the assessment and planning of health actions. Cases of TB are recorded by the Brazilian Notifiable Diseases Surveillance System [Sistema de Informação de Agravos de Notificação (SINAN)] based on data abstracted from forms used in the investigation and follow-up of cases. SINAN is the main survey system for collection and analysis of national data on TB in Brazil $[11,12]$.

A cross-sectional study was performed including all cases of TB in Brazil reported to SINAN from January 1, 2007 to December 31, 2011. Lack of data in the variable "clinical form of TB" on SINAN was the only reason for exclusion from the study.

Information about the clinical form of TB is a required field on SINAN survey system. This information is entered by a healthcare provider at the time of notification of a case of TB when the diagnosis of TB has been confirmed. Although all Brazilian municipalities transmit data to SINAN, only 70\% enter their data electronically. Database update at higher hierarchical levels is routinely conducted through vertical data transfers from the municipality to the state and then onwards to the Federal level [13]. Because TB diagnosis and treatment is free of charge in Brazil and because patients must be notified in SINAN before anti-TB treatment is started, reporting of TB cases to SINAN and the national TB program is reasonably complete in Brazil.

Clinical forms of TB were classified using WHO definitions [14]. PTB was defined as TB affecting the lung parenchyma. EPTB was defined as TB affecting organs and tissues outside of the lungs (e.g. skin, pleura, bones and joints, meninges, etc.). Miliary TB was classified as extrapulmonary TB. Information on sites of extrapulmonary disease (pleural, lymphatic, genitourinary, bone, eye, skin, laryngeal, miliary, meningitis and others) is routinely captured in the SINAN data base [15].

First, a descriptive analysis of the absolute and relative frequencies of patients presenting with pulmonary or extrapulmonary $\mathrm{TB}$, both pulmonary and extrapulmonary $\mathrm{TB}$, and disease at various extrapulmonary sites (pleural, lymphatic, genitourinary, bone, eye, skin, miliary and others) was done. Then, characteristics of cases of exclusively EPTB and exclusively PTB were compared. Cases of PTB + EPTB were excluded from this stage because these forms of $\mathrm{TB}$ affect pulmonary and extrapulmonary sites simultaneously, and the cases could not be allocated to either group leading to possible classification bias. Excluding such cases is similar to methods used in a recent national study of extrapulmonary $\mathrm{TB}$ in the USA [16].

Pearson's chi-square test was used to compare the rates of PTB and ЕРTB. Variables with a P value $<0.05$ were included in a hierarchical logistic regression model.
Study variables were assessed and allocated into five levels: Level 1 (sociodemographic) variables included gender (female or male), age ( 0 to 14 years, 15 to 24 years, 25 to 34 years, 35 to 44 years, 45 to 54 years, 55 to 64 years, more than 65 years), ethnicity (white, black, brown, Asian or Indian), and educational level (illiterate, 1 to 4 years of education, 5 to 8 years, 9 to 12 years, greater than 12 years, non-applicable); Level 2 (environmental) variables included residence (urban, rural, or peri-urban), and institutionalization [yes (prison, nursing home, orphanage, hospital, psychiatric institution, or others) or no]. Level 3 (previous comorbidities) variables included HIV/AIDS (negative or positive), alcoholism (yes or no), diabetes (yes or no), mental illness (yes or no), and other diseases (yes or no). Level 4 (clinical features) variables included admission type (new case, relapse, readmission following dropout, unknown, or transfer), tuberculin skin test (TST) [positive $(>5 \mathrm{~mm})$ or negative $(0$ to $4 \mathrm{~mm})$ ], sputum smear test for acid-fast bacilli (AFB) (negative or positive), culture (positive or negative), histopathology [positive (positive AFB and suggestive of $\mathrm{TB}$ ) or negative TB. Level 5 (treatment outcome of $\mathrm{TB}$ ) variables included anti-TB treatment administered under Directly Observed Therapy (DOT) (yes or no) and outcome status [cure, dropout, death by $\mathrm{TB}$, death due to other causes, transfer, or multidrug resistant TB (MDR-TB)].

Tuberculosis is a disease with a complex causal chain. Constructing a hierarchical model may be a better way to capture the interrelationships between its determinants. In this model, variables are included from distal to proximal ones, according to different levels of a causal network arising from a robust theoretical base $[17,18]$. Associations resulting from the hierarchical regression model are adjusted for the variables in the same level and those in previous levels, taking into account both confounders and mediators $[17,18]$.

The present model was based on the conceptual framework for social determinants of TB formulated by Maciel [19]. Independent variables were hierarchized into five levels: socio-demographic (Level 1), environmental (Level 2), previous comorbidities (Level 3), clinical features of TB (Level 4), and outcome of anti-TB treatment (Level 5), as outlined above.

Distinct models were used in building each level and the variables that exhibited an association with the clinical form of TB $(p \leq 0.05)$ at each level were included in the subsequent level, resulting in the following models: level 1 - sociodemographic characteristics; level 2 - variables included from level $1+$ environmental characteristics; level 3 - variables included from level 2 + comorbidities; level 4 - variables included from level 3 + clinical characteristics of TB; and level 5 - variables included from level 4 + outcome variables. 
Microsoft Excel 2010 software was used to construct the databases and generate the graphs. Statistical analysis was performed with Stata version 11.0, and included calculation of odds ratios (OR) with 95\% confidence intervals (95\% CI).

The study was approved by the research ethics committee of the Center of Health Science of the Federal University of Espírito Santo (UFES) - Record Number 121/06. The institutional review board of UFES granted permission for use of information from the SINAN database for the purposes of the study and waived the need for written informed consent from participants as the study involved only secondary data and the confidentiality of the patients' identities was protected.

\section{Results}

\section{Study population}

Between 2007 and 2011, 428,039 cases of TB were reported to SINAN. Of these, $491(0.11 \%)$ were excluded because the clinical form of $\mathrm{TB}$ was not entered into SINAN, resulting in a final sample of 427,548 cases. The sample included 356,342 cases of PTB (83.35\%; 95\% CI 83.23\% - 83.45\%), 57,217 cases of EPTB (13.37\%; 95\% CI $13.28 \%-13.48 \%), 13,989$ cases of PTB + ЕРТВ (3.27\%; 95\% CI $3.21 \%-3.32 \%)$. The total number of cases of TB with some type of extrapulmonary disease (all forms except PTB) was 71,207. In 70,131 of such cases, the clinically affected sites were recorded in SINAN. Their relative proportions are depicted in Figure 1. Only the first site of disease reported is depicted in the figure. In 4,307 (6\%) cases of EPTB or PTB + EPTB, a second site was also involved. Among these secondary's sites of TB, 27.8\% involved lymph nodes, $18.8 \%$ pleural, $10.5 \%$ miliary, $8.4 \%$ laryngeal, $5.4 \%$ meningeal, $4.4 \%$ bone, $3.3 \%$ skin, $2.6 \%$ genitourinary, $1.1 \%$ ocular and $17.7 \%$ others.

The following characteristics of patients with EPTB were prominent in the descriptive analysis: male gender (60.7\%), age of 0 to 15 years old (24.6\%), white race (16.7\%), and history of five to eight years of education (29.1\%). The proportion of cases without HIV result was $39.2 \%$; furthermore, $50.2 \%$ of the patients were not treated under DOT and $22.4 \%$ had no information about this variable, $9.4 \%$ of the cases were transferred out, and $71.5 \%$ were cured (data not shown). Other features of the cases of EPTB compared to PTB are described in Tables 1 and 2.

\section{Comparative analysis: EPTB versus PTB}

Although both PTB and EPTB were more prevalent in males, the proportion of females with EPTB was higher $(\mathrm{p}<0.001)$. A significant difference was also observed in the age distribution between PTB and EPTB cases. Patients aged less than fourteen years old had EPTB more frequently than PTB $(\mathrm{p}<0.001)$ (Table 1$)$.

Among cases of EPTB, the proportion of white individuals and of individuals with more than seven years of education was significantly greater $(\mathrm{p}<0.001$ for both, Table 1$)$. Alcoholism $(\mathrm{p}<0.001)$, diabetes mellitus

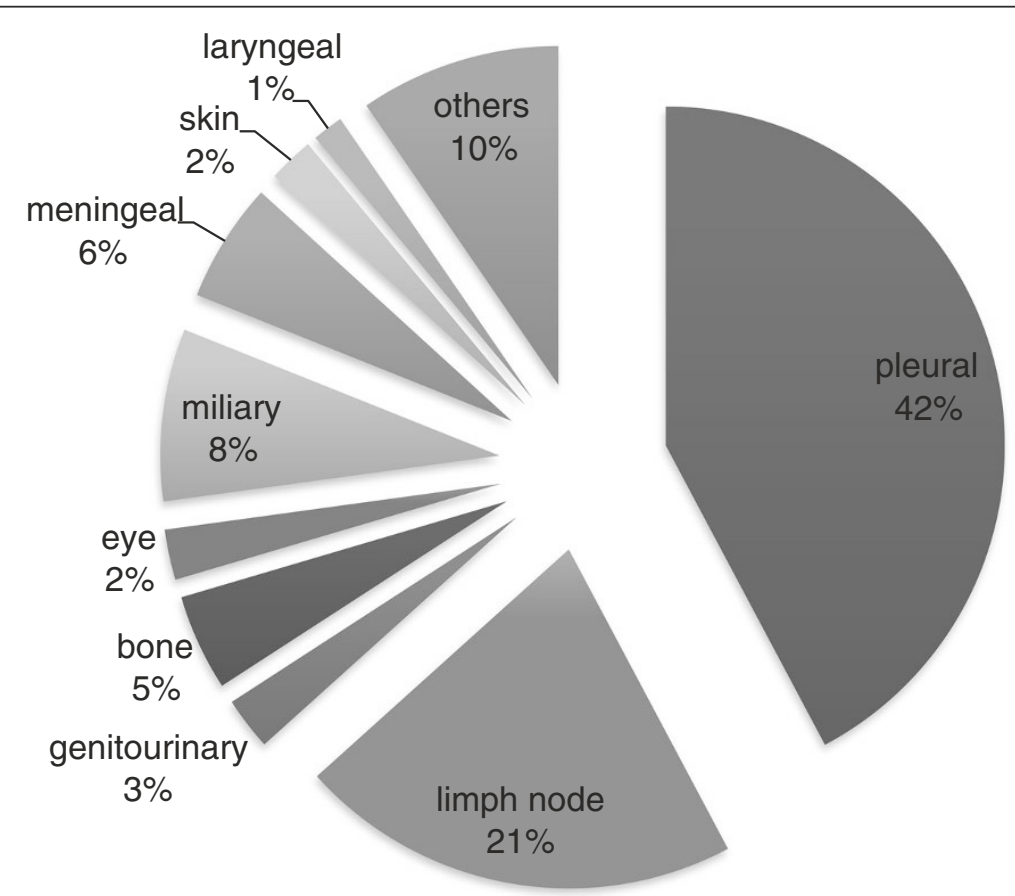

Figure 1 Clinical sites of extrapulmonary tuberculosis in Brazil, 2007 to 2011. 
Table 1 Sociodemographic characteristics of EPTB and PTB in Brazil, 2007 - 2011

\begin{tabular}{|c|c|c|c|c|}
\hline Characteristics $\mathrm{N}^{*}$ & Categories & EPTB $(\%)(n=53,853)$ & PTB $(\%)(n=356,341)$ & P value $* *$ \\
\hline Gender & Female & 22,472 (39.3) & $115,541(32.4)$ & $<0.001$ \\
\hline$(413,533)$ & Male & $34,743(60.7)$ & 240,777 (67.6) & \\
\hline Age & 0-14 years old & $3,743(6.4)$ & $10,733(3.0)$ & $<0.001$ \\
\hline \multirow[t]{6}{*}{$(409,981)$} & $15-24$ years old & $7,543(14.0)$ & 60,798 (17.1) & \\
\hline & $25-34$ years old & $13,219(24.6)$ & $85,045(23.9)$ & \\
\hline & $35-44$ years old & $11,349(21.2)$ & 70,565 (19.8) & \\
\hline & $45-54$ years old & $8,616(16.0)$ & $61,198(17.2)$ & \\
\hline & 55 - 64 years old & $5,040(9.4)$ & $36,748(10.3)$ & \\
\hline & $>65$ years old & $4,545(8.4)$ & $31,064(8.7)$ & \\
\hline Skin color/race & White & $22,474(45.2)$ & $112,112(36.0)$ & $<0.001$ \\
\hline \multirow[t]{4}{*}{$(361,362)$} & Black & 6,333 (12.8) & 47,566 (15.3) & \\
\hline & Brown & 19,791 (39.9) & $144,380(46.3)$ & \\
\hline & Asian & $557(1.1)$ & $3,531(1.1)$ & \\
\hline & Indigenous & $506(1.0)$ & $4,112(1.3)$ & \\
\hline Education & Illiterate & $1,432(4.1)$ & $18,873(8.4)$ & $<0.001$ \\
\hline \multirow[t]{5}{*}{$(258,978)$} & $1-4$ years & $8,662(24.6)$ & $77,014(34.4)$ & \\
\hline & $5-8$ years & $10,242(29.1)$ & 69,786 (31.2) & \\
\hline & $9-12$ years & $8,493(24.2)$ & $39,089(17.5)$ & \\
\hline & $>12$ years & $4,490(12.8)$ & $11,818(5.3)$ & \\
\hline & Non-applicable & $1,818(5.2)$ & $7,261(3.2)$ & \\
\hline Dwelling & Urban & $37,948(91.3)$ & $241,956(88.2)$ & $<0.001$ \\
\hline \multirow[t]{2}{*}{$(315,989)$} & Rural & $3,311(8.0)$ & $30,260(11.0)$ & \\
\hline & Peri-urban & $273(0.7)$ & $2,241(0.8)$ & \\
\hline Institutionalization & No & 45,605 (93.3) & 270,977 (88.8) & $<0.001$ \\
\hline$(354,189)$ & Yes & $3,249(6.7)$ & $34,358(11.2)$ & \\
\hline
\end{tabular}

*Number of valid observations. **Pearson's chi-squared test.

EPTB: Extrapulmonary tuberculosis. PTB: pulmonary tuberculosis.

( $\mathrm{p}<0.001)$ and mental illness $(\mathrm{p}<0.001)$ occurred more frequently among patients with $\mathrm{PTB}$, whereas the proportion of patients co-infected with HIV $(\mathrm{p}<0.001)$ and having other co-morbidities diseases $(\mathrm{p}=0.001)$ was greater among patients with EPTB (Table 2).

Table 2 demonstrates that the proportions of new cases, readmission cases following dropout, relapse cases, unknown admission type cases, and transfer cases were greater for EPTB than PTB. Although the percentages of positive and negative TST were similar between EPTB and PTB, the difference was statistically significant ( $p<0.001$; Table 2). PTB patients were less frequently subjected to tissue biopsy and histopathological examination for diagnosis $(p<0.001)$, but were more often treated under DOTS $(p<0.001)$. The number of deaths due to pulmonary forms of TB was greater than the number of deaths due to EPTB, and the number of deaths due to other causes was higher for EPTB ( $<0.001$; Table 2).

Due to the significance found with the chi-squared test (Tables 1 and 2), all of the investigated variables were included in the hierarchical model and remained significant during the various stages of analysis as demonstrated in Tables 3 and 4.

Males and institutionalized patients were less likely to have ЕPTB (OR 0.77; 95\% CI 0.76 - 0.78) and (OR 0.61; $95 \%$ CI $0.59-0.64$ ), respectively (Table 3 ).

ЕРТВ patients were more likely to be white, less than fourteen years old (OR 2.52; 95\% CI $2.39-2.65$ ), have more than 12 years of education (OR 4.93; 95\% CI $4.61-5.28$ ), and be HIV seropositive (OR 2.15; 95\% CI $2.09-2.21$ ) (Table 3).

Table 4 describes 3 levels of the hierarchical logistic regression model. Level 2 which corresponds to comorbidities show that alcoholism (OR 0.46; 95\% CI $0.43-$ 0.46), mental illness (OR 0.88; 95\% CI 0.82 - 0.95), and diabetes mellitus (OR 0.54; 95\% CI $0.51-0.57$ ) occurred less frequently in patients with ЕРTB compared to those with PTB. The variables corresponding to level 4 associated with EPTB included admission due to transfer (OR 1.31; $95 \%$ CI 1.24 - 1.37), positive TST (OR 1.08; $95 \%$ 
Table 2 Comorbidities, clinical features, and treatment outcomes of EPTB and PTB in Brazil, 2007- 2011

\begin{tabular}{|c|c|c|c|c|}
\hline Characteristics $\mathrm{N}^{*}$ & Categories & EPTB $(\%)(n=53,853)$ & PTB $(\%)(n=356,341)$ & P value ${ }^{* *}$ \\
\hline HIV/AIDS & Negative & $24,072(69.2)$ & $149,526(83.8)$ & $<0.001$ \\
\hline$(213,336)$ & Positive & $10,755(30.8)$ & $28,983(16.2)$ & \\
\hline Alcoholism & No & $46,056(91.6)$ & $249,995(82.0)$ & $<0.001$ \\
\hline$(355,292)$ & Yes & $4,236(8.4)$ & $55,005(18.0)$ & \\
\hline Diabetes & No & $48,121(96.1)$ & $279,415(92.9)$ & $<0.001$ \\
\hline$(350,756)$ & Yes & $1,960(3.9)$ & $21,260(7.1)$ & \\
\hline Mental illness & No & $49,114(98.1)$ & 293,039 (97.3) & $<0.001$ \\
\hline$(351,236)$ & Yes & $960(1.9)$ & $8,123(2.7)$ & \\
\hline Other diseases & No & $38,142(83.8)$ & $229,706(84.7)$ & 0.001 \\
\hline$(316,784)$ & Yes & $7,357(16.2)$ & $41,579(15.3)$ & \\
\hline Admission type & New cases & $50,126(87.6)$ & $290,431(81.5)$ & $<0.001$ \\
\hline \multirow[t]{4}{*}{$(413,559)$} & Relapse & $2,178(3.8)$ & $23,013(6.5)$ & \\
\hline & Readmission after dropout & $1,386(2.4)$ & $23,191(6.5)$ & \\
\hline & Unknown & $151(0.3)$ & $1,026(0.3)$ & \\
\hline & Transfer & $3,376(5.9)$ & $18,681(5.2)$ & \\
\hline TST & Negative & $4,745(29.3)$ & $14,461(28.0)$ & $<0.001$ \\
\hline$(67,942)$ & Positive & $11,481(70.7 .2)$ & $37,255(72.0)$ & \\
\hline AFB smear & Negative & $23,936(80.0)$ & $82,602(26.5)$ & $<0.001$ \\
\hline$(341,807)$ & Positive & $5,997(20.0)$ & $229,272(73.5)$ & \\
\hline Culture & Negative & $6,775(59.3)$ & $22,103(33.2)$ & $<0.001$ \\
\hline$(78,004)$ & Positive & $4,648(40.7)$ & $44,478(66.8)$ & \\
\hline Histopathology & Negative & 884 (3.8) & 2,184 (9.9) & $<0.001$ \\
\hline$(44,855)$ & Positive & $21,903(96.2)$ & $19.884(90.1)$ & \\
\hline DOT & Not performed & $28,727(64.7)$ & $153.811(51.7)$ & $<0.001$ \\
\hline$(341,831)$ & Performed & $15,696(35.3)$ & $143,597(48.3)$ & \\
\hline Outcome status & Cure & $30,186(71.5)$ & $186,428(70.1)$ & $<0.001$ \\
\hline \multirow[t]{5}{*}{$(308,112)$} & Dropout & $3,429(8.1)$ & $33,016(12.4)$ & \\
\hline & Death by TB & $1,564(3.7)$ & $10,718(4.0)$ & \\
\hline & Death by other causes & $3,024(7.2)$ & $11,046(4.2)$ & \\
\hline & Transfer & $3,967(9.4)$ & $23,566(8.9)$ & \\
\hline & MDR-TB & $28(0.1)$ & $1,140(0.4)$ & \\
\hline
\end{tabular}

*Number of valid observations. **Pearson's chi-squared test.

HIV/AIDS: human immunodeficiency virus/acquired immunodeficiency syndrome. TST: tuberculin skin test. AFB: acid-fast bacilli. DOT: Directly Observed Therapy. EPTB: Extrapulmonary tuberculosis. PTB: pulmonary tuberculosis.

CI 1.02 - 1.13), and positive histopathological examination (OR 3.57; 95\% CI 3.24 - 3.92). The variables in level 4 that exhibited the least association with EPTB were positive AFB smear test result (OR 0.12; 95\% CI $0.12-0.13$ ) and culture performed (OR 0.64; 95\% CI $0.60-0.37)$.

Regarding the outcome variables, treatment was administered under DOT less frequently in patients with EPTB than PTB (OR 0.69; 95\% CI 0.67 - 0.71), and patients with EPTB were less likely to default during treatment than patients with PTB (OR 0.79; 95\% CI 0.76 0.83) (Table 4).

\section{Discussion}

In Brazil, although EPTB primarily affects adults, onefourth of all cases of EPTB occurred in children less than 14 years of age. The age variable was not normally distributed in our dataset. Thus, we built different models including this variable as continuous and categorical. The model with the better fit was with categorical variable (Akaike Information Criterion (AIC) $=312853$ to continuous and $\mathrm{AIC}=310940$ to categorical). Also, the choice of categories took into account those described in the "Revised international definitions in tuberculosis control" [20]. Other affected groups include whites, 
Table 3 Hierarchical logistic regression of forms of TB and sociodemographic characteristics, Brazil, 2007 - 2011

\begin{tabular}{|c|c|c|c|c|}
\hline Level & Characteristics & & $\mathrm{OR} *$ & $\mathrm{Cl}(95 \%) * *$ \\
\hline \multirow[t]{20}{*}{ Level 1} & Gender & Female & \multicolumn{2}{|c|}{ Reference } \\
\hline & & Male & 0.77 & $0.76-0.78$ \\
\hline & Age & $0-14$ years old & 2.52 & $2.39-2.65$ \\
\hline & & 15 - 24 years old & 0.76 & $0.74-0.78$ \\
\hline & & 25 - 34 years old & \multicolumn{2}{|c|}{ Reference } \\
\hline & & $35-44$ years old & 1.11 & $1.08-1.14$ \\
\hline & & $45-54$ years old & 0.99 & $0.96-1.02$ \\
\hline & & $55-64$ years old & 1.00 & $0.96-1.03$ \\
\hline & & $>60$ years old & 1.13 & $1.09-1.17$ \\
\hline & Skin color/race & White & \multicolumn{2}{|c|}{ Reference } \\
\hline & & Black & 0.75 & $0.72-0.77$ \\
\hline & & Brown & 0.75 & $0.73-0.77$ \\
\hline & & Asian & 0.82 & $0.75-0.90$ \\
\hline & & Indigenous & 0.63 & $0.57-0.70$ \\
\hline & Education & Illiterate & \multicolumn{2}{|c|}{ Reference } \\
\hline & & $1-4$ years & 1.49 & $1.39-1.58$ \\
\hline & & $5-8$ years & 2.00 & $1.88-2.13$ \\
\hline & & $9-12$ years & 3.09 & $2.90-3.29$ \\
\hline & & $>12$ years & 4.93 & $4.61-5.28$ \\
\hline & & Non-applicable & 2.19 & $2.07-2.33$ \\
\hline \multirow[t]{5}{*}{ Level 2} & Dwelling & Urban & \multicolumn{2}{|c|}{ Reference } \\
\hline & & Rural & 0.82 & $0.79-0.85$ \\
\hline & & Peri-urban & 0.89 & $0.78-1.01$ \\
\hline & Institutionalization & No & \multicolumn{2}{|c|}{ Reference } \\
\hline & & Yes & 0.61 & $0.59-0.64$ \\
\hline
\end{tabular}

*OR: Odds Ratio of EPTB outcomes compared to PTB **Cl: confidence interval. HIV/AIDS: human immunodeficiency virus/acquired immunodeficiency syndrome. EPTB: extrapulmonary tuberculosis. PTB: pulmonary tuberculosis.

individuals with 5 to 8 years of formal education, residents of urban areas, and non-institutionalized individuals. Histopathological examination of affected sites and tissues is usually recommended for diagnosis, and a large number of samples from patients with EPTB are AFB positive. The low proportion of patients with extrapulmonary TB treated under DOT should alert the national TB control program to the possible underuse of DOT in patients with EPTB and potentially lower cure rates in such patients. The high rate of transfers suggests the difficulties or lack of knowledge associated with the management of patients with EPTB.

Limitations of our study include deficiencies in the secondary databases including, possible missing or incomplete data, and potential biases and errors during data entry. We analyzed data for patients with pulmonary and extrapulmonary forms of TB. Additional studies of patients with combined pulmonary and extrapulmonary
TB are needed to understand the characteristics of such patients.

Nevertheless, because the number of TB cases in our study was large and national TB surveillance data in Brazil are reasonably complete, our statistical analysis is robust and remains significant. In addition, it is believed that ЕРTB might be underreported due to its difficult diagnosis, which requires a high degree of clinical suspicion and biopsy or culture for confirmation. Strengths of our study include its national scope, the use of a hierarchical logistic regression model, and its new contribution to the knowledge about EPTB in Brazil.

We found that the most frequent site of EPTB was the pleura, followed by the peripheral lymph nodes. In the US between 1993 and 2006, the lymph node was the most common site of extrapulmonary involvement, followed by the pleura [16]. Tuberculous pleurisy occurs frequently in association with PTB. Moreover, evidence suggests that pleural TB represents an early manifestation of primary infection by Mycobacterium tuberculosis (MTB) and may serve as a sentinel event in recent transmission studies [21].

The proportion of cases of EPTB relative to the other clinical forms of TB exhibits wide variation among different countries and seems to be higher in those with a low incidence of $\mathrm{TB}$, such as the US (21\%), Italy (32\%), Japan (23\%) and Australia (39\%) [1]. The reasons for these differences are unknown but could be related to different epidemiological patterns and the proportions of persons with TB as a consequence of recent (as opposed to remote) infection [21]. It is believed that in these in developed countries the proportion of patients with PTB, primarily responsible for the transmission of $\mathrm{TB}$ to other persons is lower, under such conditions ЕРТВ has become more perceptive in actual epidemiological studies. Also the subnotifications of EPTB due the intrinsic difficulties in EPTB diagnosis and the lack of access to adequate diagnostic infrastructure in high TB burden developing countries could have also contributed to the observed EPTB disparity between the TB high burden developing countries and low incidence developed countries.

Conversely, in countries with a high incidence of TB, EPTB usually represents a smaller fraction of all cases. In 2011, the proportion of ЕРTB was 19\% in India, $4 \%$ in Indonesia, and 18\% in Pakistan. Our study demonstrated that the proportion of EPTB was $12.6 \%$ which is similar to high TB burden countries $[1,9]$.

The higher proportion of females in EPTB cases compared with PTB cases was statistically significant, confirming other studies [16,22-24]. The association between white race and EBTB found in the present study disagrees with the results found in a US study where $81 \%$ of cases of EPTB occurred among non-whites [16]. Investigators in 
Table 4 Hierarchical logistic regression of forms of TB and clinical characteristics, Brazil, $2007-2011$

\begin{tabular}{|c|c|c|c|c|}
\hline Level & Characteristics & & OR * & $\mathrm{Cl}(95 \%) * *$ \\
\hline \multirow[t]{10}{*}{ Level 3} & HIV/AIDS & Negative & Reference & \\
\hline & & Positive & 2.15 & $2.09-2.21$ \\
\hline & Alcoholism & No & Reference & \\
\hline & & Yes & 0.45 & $0.43-0.46$ \\
\hline & Diabetes & No & Reference & \\
\hline & & Yes & 0.54 & $0.51-0.57$ \\
\hline & Mental illness & No & Reference & \\
\hline & & Yes & 0.88 & $0.82-0.95$ \\
\hline & Other diseases & No & Reference & \\
\hline & & Yes & 1.18 & $1.15-1.22$ \\
\hline \multirow[t]{13}{*}{ Level 4} & Admission type & New cases & Reference & \\
\hline & & Relapse & 0.65 & $0.62-0.69$ \\
\hline & & $\begin{array}{l}\text { Readmission after } \\
\text { dropout }\end{array}$ & 0.39 & $0.37-0.42$ \\
\hline & & Unknown & 0.66 & $0.53-0.81$ \\
\hline & & Transfer & 1.31 & $1.24-1.37$ \\
\hline & TST & Negative & Reference & \\
\hline & & Positive & 1.08 & $1.02-1.13$ \\
\hline & AFB smear & Negative & Reference & \\
\hline & & Positive & 0.12 & $0.12-0.13$ \\
\hline & Culture & Negative & Reference & \\
\hline & & Positive & 0.64 & $0.60-0.67$ \\
\hline & Histopathology & Negative & Reference & \\
\hline & & Positive & 3.57 & $3.24-3.92$ \\
\hline \multirow[t]{8}{*}{ Level 5} & DOT & Not performed & Reference & \\
\hline & & Performed & 0.69 & $0.67-0.71$ \\
\hline & Exit condition & Cure & Reference & \\
\hline & & Dropout & 0.79 & $0.76-0.83$ \\
\hline & & Death by TB & 0.73 & $0.68-0.79$ \\
\hline & & $\begin{array}{l}\text { Death by other } \\
\text { causes }\end{array}$ & 1.05 & $1.00-1.12$ \\
\hline & & Transferal & 1.24 & $1.18-1.30$ \\
\hline & & MDR-TB & 0.43 & $0.27-0.68$ \\
\hline
\end{tabular}

*OR: Odds Ratio of EPTB outcomes compared to PTB ${ }^{*} \mathrm{Cl}$ : confidence interval TST: tuberculin skin test. AFB: acid-fast bacilli. DOT: Directly Observed Therapy. EPTB: extrapulmonary tuberculosis. PTB: pulmonary tuberculosis.

the UK and Germany have reported that EPTB is more prevalent among particular racial groups, such as Asians, whereas it is less frequent among Caucasians $[10,23]$. In another Brazilian study of 606 patients with $\mathrm{TB}$ an association between EPTB and white race was also present [25]. The predominance of the white race also differs between the cases of PTB in Brazil, where individuals of brown and black ethnicity are most affected by PTB [10].
Our analysis also demonstrated that a higher education level was associated with a higher frequency of EPTB. In Brazil this result may be related to easier access to diagnostic and health services among more educated individuals, given that the diagnosis of ЕРTB often requires invasive sampling procedures with additional expense and risk, and the collection of such samples is more difficult in public health services of resource-constrained countries [26]. We were unable to identify other international studies examining educational level and extrapulmonary TB to compare our findings.

Regarding clinical factors, our analysis confirms many earlier reports $[4,6,10,16,27]$ of the strong association between HIV co-infection and extrapulmonary TB. In a Brazilian study on TB-HIV coinfection between 2006 and 2010, EPTB occurred in $26.2 \%$ of HIV-infected patients [28]. In a recent meta-analysis, the pooled analysis showed a significant relationship between HIV infection and ЕРTB (OR:1.3, CI 1.05-1.6) [29].

The fact that $39.9 \%$ of the cases of EPTB were awaiting HIV test results or were not tested deserves particular attention. A smaller number of patients with TB who are tested for HIV correlates with a greater uncertainty relative to the prevalence of coinfection [30]. All patients who give consent must be tested for HIV, and mechanisms should be established to ensure that the results are systematically included in information systems as soon as they become available [30].

The most frequent type of admission of patients with EPTB to the health system was through transfers. This phenomenon may be related to the greater difficulty of health professionals in peripheral health units to confidently diagnose EPTB; thus, it is necessary to refer patients to other services for diagnostic confirmation or to begin treatment without confirmation based on a high degree of clinical suspicion and negative AFB smear results [31].

Mycobacterial cultures are not universally performed during evaluation of TB suspects in Brazil and are indicated only in specific instances, such as in cases of suspected EPTB or drug resistant TB and in vulnerable populations [32]. For this reason, cultures were performed in a larger proportion of cases of EРTB compared with PTB in our study, although cultures were positive in a smaller fraction of EPTB patients.

Anti-TB treatment was not conducted under DOT in $64.7 \%$ of the cases of EPTB, which is significantly higher compared with PTB cases. Among the recommendations for the treatment of EPTB, lack of adherence, poor absorption of anti-TB drugs, and drug resistance must be considered as possible reasons for the delayed or suboptimal response to appropriate treatment, and DOT is strongly recommended to enhance treatment completion and cure of the patient [33]. 
EPTB is an important health problem due to its high mortality and morbidity rates, both in developing and developed countries [34]. EPTB is less contagious, less frequent than PTB, and less well addressed by programs in developing countries, but improved diagnosis of extrapulmonary forms of TB and supervised treatment are essential prerequisites for optimizing care and better treatment outcomes [35].

Knowledge about determinants and characteristics of patients with EPTB from our study should motivate more investigation of extrapulmonary involvement to improve patient care and TB control in Brazil.

\section{Conclusions}

As can be seen in our study, characteristics of EPTB often differ from those of PTB, as well as from those reported in countries with a low burden of TB. Therefore, studies aiming at these differences are important.

Beyond identification of EPTB cases, special diagnostic methods like aspirates and biopsies must be guaranteed but the resources to do them are limited in many parts of Brazil. Improved diagnostic capacity is essential for better case finding and management of EPTB. Because EPTB is less infectious to others in the community, it may receive less attention than smear-positive PTB from TB programs and health units with limited resources. More specific programs and resources are needed to improve the diagnosis, treatment and outcome of EPTB in Brazil.

\section{Competing interests}

The author(s) declare that they have no competing interests.

\section{Authors' contributions}

All authors made substantive intellectual contributions to the study and read and approved the final manuscript. TG designed the study, analysed the data and drafted the manuscript. BR analysed the data and revised the

manuscript. $A B, J \sqcup J$ and $L W R$ critically reviewed and revised the manuscript. ELM was involved in the acquisition of the data, analysis and interpretation of data, and revision of the manuscript. All authors read and approved the final manuscript.

\section{Acknowledgements}

This study was supported by CNPq/Brazil edital Doenças negligenciadas 2012 and Universal 2010, the U.S. National Institutes of Health, under contract ICOHRTA 5 U2R TW006883-02, and FAPES (Fundação de Amparo à Pesquisa do Espírito Santo).

\section{Author details}

${ }^{1}$ Laboratory of Epidemiology, Universidade Federal do Espírito Santo, Vitória, ES, Brazil. '2Departament of Statistics, Universidade Federal do Espírito Santo, Vitória, ES, Brazil. ${ }^{3}$ Tuberculosis Research Unit, Department of Medicine, Division of Infectious Diseases, Case Western Reserve University, Cleveland, $\mathrm{OH}$, USA. ${ }^{4}$ Division of Infectious Disease and Vaccinology, School of Public Health, University of California, Berkeley, CA, USA.

Received: 14 June 2013 Accepted: 24 December 2013 Published: 8 January 2014

\section{References}

1. World Health Organization. Tuberculosis countries profiles. [http://www.who.int/tb/country/en/]
2. Braga JU GG, Mlranda JA, Teixeira GM, Natal S, Nijjar MA, et al: Comportamento epidemiológico da tuberculose no brasil na década de 80: estudo de morbidade. J Bras Pneumol 1992, 18:119.

3. Mascarenhas MDM, Araújo LM, Gomes KRO: Perfil epidemiológico da tuberculose entre casos notificados no município de piripiri, estado do piauí, brasil. Epidemiologia e Serviços de Saúde 2005, 14:7-14.

4. Saita NM, Oliveira HB: Tuberculosis, AIDS and tuberculosis-AIDS co-infection in a large city. Rev Lat Am Enfermagem 2012, 20:769-777.

5. Boffo MMS, Mattos IG, Ribeiro MO, Oliveira Neto IC: Tuberculose associada à AIDS: características demográficas, clínicas e laboratoriais de pacientes atendidos em um serviço de referência do sul do Brasil. J Bras Pneumol 2004, 30:140-146.

6. Seiscento M, Vargas FS, Rujula MJ, Bombarda S, Uip DE, Galesi VM: Epidemiological aspects of pleural tuberculosis in the state of Sao Paulo, Brazil (1998-2005). J Bras Pneumol 2009, 35:548-554.

7. Coutinho L, Oliveira DS, Souza GF, Fernandes Filho GMS, Saraiva MG: Perfil epidemiológico da tuberculose no município de joão pessoa - PB, entre 2007-2010. Rev Bras Ciencias da Saúde 2012, 16:35-42.

8. Silva A, Monteiro SG, Figueiredo PMS: Perfil epidemiológico dos pacientes portadores de tuberculose extrapulmonar atendidos em hospital da rede pública no estado do Maranhão. Rev Bras Clin Med 2011, 9:11-14.

9. Brasil: Ministério da saúde. Boletim epidemiológico: especial tuberculose. Secretaria de Vigilância em Saúde 2012, 43:2-12.

10. Rowinska-Zakrzewska E: [Extrapulmonary tuberculosis, risk factors and incidence]. Pneumonol Alergol Pol 2011, 79:377-378.

11. Selig L, Kritski AL, Cascao AM, Braga JU, Trajman A, de Carvalho RM: Proposal for tuberculosis death surveillance in information systems. Rev Saude Publica 2010, 44:1072-1078.

12. Oliveira GP, Pinheiro RS, Coeli CM, Barreira D, Codenotti SB: Mortality information system for identifying underreported cases of tuberculosis in Brazil. Rev Bras Epidemiol 2012, 15:468-477.

13. Bierrenbach AL, Stevens AP, Gomes ABF, Noronha EF, Glatt R, Carvalho CN, Oliveira Junior JG, Souza MFM: Efeito da remoção de notificações repetidas sobre a incidência da tuberculose no Brasil. Rev Saude Publica 2007, 41:67-76.

14. World Health Organization: Global Tuberculosis Report 2012. Paris; 2012. Document Number WHO/HTM/TB/2012.6

15. Manual de recomendações para o controle da tuberculose no Brasil. [http://portal.saude.gov.br/portal/arquivos/pdf/manual_de_recomendacoes_ tb.pdf]

16. Peto HM, Pratt RH, Harrington TA, LoBue PA, Armstrong LR: Epidemiology of extrapulmonary tuberculosis in the United States, 1993-2006. Clin Infect Dis 2009, 49:1350-1357.

17. Fuchs SC, Victora CG, Fachel J: Modelo hierarquizado: uma proposta de modelagem aplicada à investigação de fatores de risco para diarréia grave. Rev Saude Publica 1996, 30:168-178.

18. Victora CG, Huttly SR, Fuchs SC, Olinto MT: The role of conceptual frameworks in epidemiological analysis: a hierarchical approach. Int J Epidemiol 1997, 26:224-227.

19. Maciel E, Publisher - Saberes: A promoção de saúde e os determinantes sociais da Tuberculose: elementos para ação. In Promoção de saúde na diversidade humana e na pluralidade de itinerários terapeuticos. Campinas, SP; 2012.

20. Revised international definitions in tuberculosis control. Int I Tuberc Lung Dis 2001, 5:213-215.

21. Ong A, Creasman J, Hopewell PC, Gonzalez LC, Wong M, Jasmer RM, Daley $\mathrm{CL}$ : A molecular epidemiological assessment of extrapulmonary tuberculosis in San Francisco. Clin Infect Dis 2004, 38:25-31.

22. Garcia-Rodriguez JF, Alvarez-Diaz H, Lorenzo-Garcia MV, Marino-Callejo A, Fernandez-Rial A, Sesma-Sanchez P: Extrapulmonary tuberculosis: epidemiology and risk factors. Enferm Infecc Microbio/ Clin 2011, 29:502-509.

23. Forssbohm M, Zwahlen M, Loddenkemper R, Rieder HL: Demographic characteristics of patients with extrapulmonary tuberculosis in Germany. Eur Respir J 2008, 31:99-105.

24. Hoa NB, Wei C, Sokun C, Lauritsen JM, Rieder HL: Characteristics of tuberculosis patients at intake in Cambodia, two provinces in China, and Vietnam. BMC Public Health 2011, 11:1471-2458.

25. Gomes T, Vinhas SA, Reis-Santos B, Palaci M, Peres RL, Aguiar PP, Ribeiro FK, Marques HS, Dettoni VD, Johnson JL, et al: Extrapulmonary tuberculosis: strains and host risk factors in a large urban setting in Brazil. PLOS One 2013, 8:1-10. 
26. Hillemann D, Rusch-Gerdes S, Boehme C, Richter E: Rapid molecular detection of extrapulmonary tuberculosis by the automated GeneXpert MTB/RIF system. J Clin Microbiol 2011, 49:1202-1205

27. Abraham BK, Winston CA, Magee E, Miramontes R: Tuberculosis among Africans living in the United States, 2000-2009. Journal of immigrant and minority health/Center for Minority Public Health 2012, 15:381-389.

28. Barbosa IRCI: A emergencia da co-infecção Tuberculose - HIV no Brasil. HYGEIARevista Brasileira de Geografia Médica e da Saúde 2012, 8:232-244.

29. Naing C, Mak JW, Maung M, Wong SF, Kassim Al: Meta-analysis: the association between HIV infection and extrapulmonary tuberculosis. Lung 2013, 191:27-34.

30. Carvalho CN, Dourado I, Bierrenbach AL: Underreporting of the tuberculosis and AIDS comorbidity: an application of the linkage method. Rev Saude Publica 2011, 45:548-555.

31. Portillo-Gomez L, Morris SL, Panduro A: Rapid and efficient detection of extra-pulmonary mycobacterium tuberculosis by PCR analysis. Int $J$ Tuberc Lung Dis 2000, 4:361-370.

32. Conde MB, Melo FA, Marques AM, Cardoso NC, Pinheiro VG, Dalcin Pde T, Machado Junior A, Lemos AC, Netto AR, Durovni B, et al: Ill brazilian thoracic association guidelines on tuberculosis. J Bras Pneumol 2009, 35:1018-1048.

33. Golden MP, Vikram HR: Extrapulmonary tuberculosis: an overview. Am Fam Physician 2005, 72:1761-1768.

34. Sankar MM, Singh J, Angelin Diana SC, Singh S: Molecular characterization of mycobacterium tuberculosis isolates from north indian patients with extrapulmonary tuberculosis. Tuberculosis (Edinb) 2012, 93:75-83.

35. Yone EW, Kengne AP, Moifo B, Kuaban C: Prevalence and determinants of extrapulmonary involvement in patients with pulmonary tuberculosis in a Sub-Saharan African country: a cross-sectional study. Scand J Infect Dis 2013, 45:104-111.

doi:10.1186/1471-2334-14-9

Cite this article as: Gomes et al:: Epidemiology of extrapulmonary tuberculosis in Brazil: a hierarchical model. BMC Infectious Diseases 2014 14:9.

\section{Submit your next manuscript to BioMed Central and take full advantage of:}

- Convenient online submission

- Thorough peer review

- No space constraints or color figure charges

- Immediate publication on acceptance

- Inclusion in PubMed, CAS, Scopus and Google Scholar

- Research which is freely available for redistribution 